Lily Ackermann, MD, ScM

Clinical Assistant Professor of Medicine, and

Section Leader for Specialty Services, Division

of Hospital Medicine, Sidney Kimmel Medical

College at Thomas Jefferson University,

Philadelphia, PA
Eric S. Schwenk, MD

Associate Professor of Anesthesiology and

Orthopedic Surgery, and Director, Orthopedic

Anesthesia, Department of Anesthesiology, Sidney Kimmel Medical College at Thomas

Jefferson University, Philadelphia, PA
Yair Lev, MD

Clinical Assistant Professor of Cardiology,

and Medical Director, Inpatient Cardiology

Unit, Department of Medicine, Division of

Cardiology, Sidney Kimmel Medical College

at Thomas Jefferson University,

Philadelphia, PA
Howard Weitz, MD

Bernard L. Segal Professor of Clinical

Cardiology Senior Associate Dean, and

Associate Chairman, Department of Medicine;

Master Clinician, Department of Medicine,

Sidney Kimmel Medical College at Thomas

Jefferson University, Philadelphia, PA

\title{
Update on medical management of acute hip fracture
}

\section{ABSTRACT}

Morbidity and mortality rates associated with acute hip fracture remain high. Over the past decade, the management of hip fracture has shifted to emphasize prompt surgical treatment, multimodal analgesia to reduce opioid use, and incorporation of enhanced recovery pathways. Preoperative evaluation focuses on acutely correctable problems, with the understanding that delaying surgery may worsen the outcome. Prophylaxis of venous thromboembolism, treatment of preoperative anemia and acute kidney injury, and cardiac stabilization are important measures to reduce morbidity. Multimodal analgesia incorporating regional anesthesia techniques may help prevent delirium and facilitate early participation in physical therapy to reduce complications.

\section{KEY POINTS}

Follow evidence-based guidelines to minimize unnecessary testing and delay of surgery.

To minimize delirium and facilitate postoperative ambulation, consider multimodal analgesia, including peripheral nerve blocks that help minimize the need for opioids, in enhanced recovery pathways.

The best outcomes are achieved with prompt surgical repair, which should ideally be completed within 24 hours of presentation but not later than 48 hours, except in rare cases when critical medical optimization is needed.

The use of antiplatelet agents, warfarin, and direct oral anticoagulants should not delay surgery unless the benefit of spinal over general anesthesia is overwhelming.

doi:10.3949/ccjm.88a.20149
$\mathrm{H}$ IP FRACTURES ARE THE MOST COMMON reason for urgent surgery in the elderly and often lead to long-term institutional care. ${ }^{1}$ Despite advances in perioperative management, postoperative mortality rates remain high, up to $10 \%$ in the first 30 days and $8 \%$ to $36 \%$ in the first year after repair. ${ }^{2}$ Even 10 years after fracture repair, the mortality rate due to comorbid medical conditions remains higher than in age-matched controls. ${ }^{3}$

\section{IS NONSURGICAL MANAGEMENT AN OPTION?}

Without repair, the risk of death is exceedingly high due to infectious, thrombotic, and cardiopulmonary complications related to immobility. Unless the perioperative risk of death is exceptionally high due to severe comorbid illness, repair is recommended. ${ }^{1}$ Without surgery, patients are left with significant pain, immobility, and a shortened leg.

In those who are terminally ill, cannot walk, have severe dementia, or have serious comorbid conditions, nonoperative management can be considered if pain is adequately controlled and the patient is comfortable. However, a large cohort study reported that the in-hospital mortality rate may be as high as $17.2 \%$ in those treated conservatively. ${ }^{4}$

\section{TIMING OF HIP FRACTURE REPAIR}

A landmark retrospective cohort study in 42,230 adults demonstrated that wait time (time from emergency department arrival until surgery) greater than 24 hours was associated with a higher risk-adjusted likelihood of death within 30 days (6.5\% vs 5.8\%). ${ }^{5}$ The composite outcome of other medical complications (myocardial infarction, deep vein thrombosis, 
TABLE 1

\section{Preoperative evaluation of acute hip fracture}

Preoperative condition or organ system Interventions and comments

Fall

Evaluate the cause of the fall, including cardiac and neurologic syncopal episodes. Correct complications from the fall such as rhabdomyolysis, dehydration, and acute renal failure.

Diabetes

Patients with severe hyperglycemia (glucose levels $>400 \mathrm{mg} / \mathrm{dL}$ ), ketoacidosis, or on an insulin pump: treat with an insulin infusion preoperatively with a target glucose level of $140-180 \mathrm{mg} / \mathrm{dL}$.

Patients with glucose levels $>180 \mathrm{mg} / \mathrm{dL}$ : the recommended total daily dose of insulin is $0.1-0.15 \mathrm{U} / \mathrm{kg}$, given mainly as basal insulin, with correctional insulin coverage for glucose levels $>180 \mathrm{mg} / \mathrm{dL}$ before meals and at bedtime.

Anemia, thrombocytopenia Evaluate anemia with a hemoglobin below $8 \mathrm{~g} / \mathrm{dL}$ and thrombocytopenia with a platelet count $<100 \times 10^{9} / \mathrm{L}$, and correct as needed.

\begin{tabular}{ll}
\hline $\begin{array}{l}\text { Anticoagulation before } \\
\text { admission }\end{array}$ & $\begin{array}{l}\text { Evaluate an international normalized ratio (INR) }>1.5 \text { and correct if needed. } \\
\text { It is not necessary to have a normal INR or partial thromboplastin time before } \\
\text { surgery. Assess continuation or reversal of anticoagulants. }\end{array}$ \\
\hline Respiratory & $\begin{array}{l}\text { Bronchospasm and hypoxemia require evaluation. For a patient with known } \\
\text { asthma or chronic obstructive pulmonary disease, an exacerbation identified } \\
\text { on preoperative evaluation may require acute bronchodilator therapy and } \\
\text { consideration for surgical delay. Consider spinal anesthesia. }\end{array}$ \\
\hline Renal & $\begin{array}{l}\text { Discontinue angiotensin-converting enzyme inhibitors and angiotensin II } \\
\text { receptor blockers preoperatively, and provide adequate hydration with isotonic } \\
\text { fluid. }\end{array}$ \\
\hline Cardiovascular & $\begin{array}{l}\text { High-risk cardiac conditions should not disqualify surgery. Emphasis is on } \\
\text { shared decision-making with the patient and family. }\end{array}$
\end{tabular}

functional capacity is poor or unknown, pulmonary embolism, and pneumonia) was also reduced in those undergoing surgery withuse the physical examination and ECG

to assess for high-risk cardiac conditions in 24 hours $(12.2 \%$ vs $10.1 \%)$. While the differences are not large, these results underscore the importance of timely surgery. In rare cases in which medical optimization is needed, delaying surgery up to no more than 48 hours from fracture may be necessary. ${ }^{6,7}$

\section{RISK STRATIFICATION IN THE GERIATRIC PATIENT}

The preoperative assessment should focus on stabilizing medical conditions that can be corrected, such as dehydration, hypovolemia, anemia, hypoxia, electrolyte disturbances, and arrhythmias. ${ }^{8}$ It should aim at recognizing chronic conditions that could modify the postoperative course, such as cognitive disorders and chronic cardiac, respiratory, and renal failure. ${ }^{8}$

A targeted preoperative evaluation ${ }^{9}$ is included in Table 1 . Some of the major issues of particular significance in the elderly are discussed below.

\section{Diabetes, hypoglycemia}

Avoidance of hypoglycemia in the elderly is essential, as it is associated with a longer length of hospital stay and higher risk of death, and elderly patients undergoing surgical interventions often have reduced oral intake. ${ }^{10}$

For patients with diabetes with blood glucose levels greater than $180 \mathrm{mg} / \mathrm{dL}$, the recommended total daily dose of insulin is $0.1-$ $0.15 \mathrm{U} / \mathrm{kg} /$ day, given mainly as basal insulin, with correctional insulin coverage for glucose levels above $180 \mathrm{mg} / \mathrm{dL} .{ }^{10}$

\section{Anemia}

The prevalence of preoperative anemia due to bleeding from the fracture ranges from $24 \%$ to $44 \%$, and that of postoperative anemia is even higher at $51 \%$ to $87 \% .{ }^{11}$

The FOCUS trial (Functional Outcomes 
in Cardiovascular Patients Undergoing Surgical Hip Fracture Repair) was a randomized controlled trial designed to address a transfusion goal for patients over age 50 with hip fracture who had a history of or risk factors for ischemic heart disease. ${ }^{12}$ A postoperative hemoglobin transfusion threshold of $8 \mathrm{~g} / \mathrm{dL}$ in the absence of symptomatic anemia was considered acceptable in elderly patients with or at risk of ischemic heart disease.

\section{Acute kidney injury}

Hong et $\mathrm{al}^{13}$ reported that patients who experienced acute kidney injury during hospitalization had significantly longer hospital stays and higher in-hospital and long-term mortality rates. A low preoperative albumin level, use of angiotensin-converting enzyme (ACE) inhibitors or angiotensin II receptor blockers (ARBs), the need for blood transfusion, and coronary artery disease were found to be independent risk factors for acute kidney injury. ${ }^{13}$

Aggressive hydration with isotonic fluids should be started early, and ACE inhibitors or ARBs should be held before surgery to prevent intraoperative hypotension and acute kidney injury. Doses of antihypertensive and ratecontrol drugs should be reduced to avoid hypotension. However, routine use of normal saline infusion per standing orders without evidence of dehydration or acute kidney injury should be avoided, as it can lead to peripheral fluid overload and decompensated heart failure.

\section{Cardiovascular risk}

The American College of Cardiology/American Heart Association ${ }^{14}$ and the Canadian Cardiovascular Society $(\mathrm{CCS})^{15}$ guidelines caution about indiscriminate use of preoperative testing that, in many circumstances, does not serve to reduce the patient's risk but may instead delay needed surgery. It is our policy to screen patients on admission for high-risk conditions and to use cardiology consultation or preoperative testing only when it would lead to a change in perioperative management, because delays are associated with increased mortality.

The impact of preoperative testing in terms of delaying surgery is substantial. In acute hip fractures, preoperative echocardiography and nuclear stress testing can delay surgery by up to 6 days, leading to further postoperative complications. ${ }^{16}$ In one study, echocardiogra- phy alone led to a delay of surgery of 32 to 48 hours without a demonstrable difference in complications or mortality. ${ }^{17}$

In terms of preoperative cardiac screening, cardiac consultation delayed surgery by a mean of 9.9 hours due to an overestimation of cardiac risk. ${ }^{18}$ Preoperative subspecialty consultation was associated with delays to surgery of over 24 hours, and only $37 \%$ of the time did consultation lead to an identifiable change in treatment. ${ }^{19}$

The main role of cardiology consultation should be to assist in the management of the patient who has a high-risk or unstable cardiac condition, to advise regarding risk-reduction strategies, and to assist with postoperative management.

A good exertional capacity is an excellent prognostic feature. ${ }^{14,15}$ However, if the patient has a poor or unknown functional capacity, objective data such as the physical examination and electrocardiogram should be used to assess for high-risk cardiac conditions.

We typically obtain an expedited preoperative transthoracic echocardiogram if the patient has any of the following conditions:

- Physical signs or symptoms of acute heart failure, including recently worsened dyspnea on exertion, orthopnea, and pulmonary or lower extremity edema

- Signs or symptoms suggestive of severe pulmonary hypertension

- A newly discovered murmur that raises concern for an obstructive process (eg, left ventricular intracavitary obstruction, hypertrophic obstructive cardiomyopathy)

- Clinical signs or symptoms suggesting critical aortic stenosis, such as a systolic murmur or unexplained syncope, or severe mitral stenosis in a patient who has not had an echocardiogram in the past 12 months. The finding of critical aortic stenosis, hypertrophic obstructive cardiomyopathy, or severe pulmonary hypertension may affect the anesthetic plan, including the choice of general or regional anesthesia, placement of invasive monitors, and use of vasoactive medications. We usually perform transthoracic echocardiography to estimate the degree of valve stenosis and left ventricular dysfunction. Even if severe aortic stenosis is detected in a patient who has no symptoms, hip repair surgery may be safely performed, and reduction of risk can be at-

\section{Urgent surgery increases the risk of a perioperative cardiovascular event}


tempted on an individualized basis.

While preoperative balloon aortic valvuloplasty to reduce the degree of valve stenosis has been suggested as an approach to lower the perioperative risk, the delay in surgery and the complication rate of the valvuloplasty must be considered. We do not believe that transcatheter aortic valve replacement before emergency hip surgery is a practical option, given the delay to fracture repair. Transcatheter aortic valve replacement requires a comprehensive evaluation including coronary angiography and is rarely done as an emergency procedure.

\section{Arrhythmias}

Patients with rapid atrial fibrillation, atrial flutter, or supraventricular tachycardia can proceed to surgery after the ventricular rate is controlled. Patients with advanced atrioventricular block - eg, second-degree (Mobitz type II) atrioventricular block or third-degree atrioventricular block-may require temporary pacemaker placement before surgery. Placement of a permanent pacemaker may be indicated before discharge.

\section{Medications}

Aspirin should be continued, as its effect on perioperative bleeding is minimal
ACE inhibitors and ARBs may be withheld during the 24 hours before surgery to avoid perioperative hypotension if being prescribed for essential hypertension..$^{20}$ For patients receiving an ACE inhibitor or ARB as treatment for chronic heart failure, we weigh the risks vs benefits of their discontinuation with the patient's outpatient physician, if possible, and with the anesthesiology team.

Because there is a risk of bradycardia and hypotension, we do not initiate beta blockers for patients not already receiving them in the immediate preoperative period. For patients with chronic systolic heart failure taking beta blockers before surgery, we continue these agents unless there is evidence of decompensated heart failure.

\section{Troponin}

Troponin $\mathrm{T}$ and troponin I are measured to evaluate the diagnosis of an acute cardiac injury. A troponin level is often drawn on admission to evaluate for a possible ischemic cause of syncope. Troponin is frequently elevated in patients with renal insufficiency in the absence of acute myocardial injury. It may be elevated due to chronic congestive heart failure and should be considered a marker of poorer prognosis. Troponin elevation with a significant increase is concerning for type 1 or type 2 myocardial infarction. If preoperative troponin is elevated and the elevation attributed to myocardial injury or the etiology is unclear, cardiology consultation should be considered.

Most perioperative myocardial infarctions are not accompanied by classic chest pain or ST-segment elevation. In this situation, we treat patients using the same guideline-directed approach as for non-ST-elevation myocardial infarction in the nonoperative setting.

Isolated perioperative troponin elevation, without other features of myocardial infarction, is deemed myocardial injury after noncardiac surgery. In general, the risk of death within 30 days is higher in patients in whom this happens. ${ }^{21}$ Currently, the clinical significance of isolated troponin elevation in a patient who has sustained a hip fracture is unknown. If the patient is hemodynamically stable, we typically proceed to hip repair surgery with enhanced surveillance in the postoperative period. After surgery, we decide whether an assessment of myocardial perfusion is warranted for risk assessment.

\section{Risk assessment}

Repair of an acute hip fracture is urgent surgery, and hip fracture is considered an intermediate-risk surgery, with a $1 \%$ to $5 \%$ risk of major adverse cardiac events. ${ }^{14}$ Elderly patients with hip fractures are frail, and many have a poor or unknown functional status and risk factors for cardiac disease. Urgent surgery increases the risk of a perioperative cardiovascular event.

As preoperative pharmacologic stress testing leads to delays without a clear benefit in acute hip fractures, we follow the CCS guidelines, ${ }^{15}$ which do not include pharmacologic stress testing preoperatively for perioperative cardiovascular risk estimation. Instead, they recommend risk stratification using the Revised Cardiac Risk Index. The CCS also uses preoperative $\mathrm{N}$-terminal pro-brain natriuretic peptide or B-type natriuretic peptide (BNP) measurement to aid in risk stratification and recommends postoperative troponin measurement to detect myocardial infarction. 


\section{TABLE 2}

\section{Pain control in acute hip fracture}

\section{Dose}

Comments

\begin{tabular}{|c|c|c|}
\hline \multicolumn{3}{|l|}{ First line: nonopioid analgesia } \\
\hline $\begin{array}{l}\text { Peripheral nerve block (femoral } \\
\text { nerve block, fascia iliaca block) }\end{array}$ & $\begin{array}{l}\text { Ropivacaine } 0.5 \%, 15-20 \mathrm{~mL} \text { in primary } \\
\text { block; if catheter placed, infusion may } \\
\text { be run with ropivacaine } 0.2 \% \text { at } 8-10 \\
\mathrm{~mL} / \text { hour }\end{array}$ & Quadriceps weakness can be a limitation \\
\hline Acetaminophen & $\begin{array}{l}1,000 \mathrm{mg} \text { intravenously or orally every } \\
6 \text { hours }\end{array}$ & $\begin{array}{l}\text { For patient weighing }<50 \mathrm{~kg} \text {, } \\
\text { orally } 650 \mathrm{mg} \text { every } 6 \text { hours }\end{array}$ \\
\hline Celecoxib & 200 mg orally twice a day & $\begin{array}{l}\text { Use if glomerular filtration rate is } \\
>60 \mathrm{~mL} / \mathrm{min}\end{array}$ \\
\hline Ibuprofen & $400 \mathrm{mg}$ by mouth every 6 hours & Use if glomerular filtration rate is $>60 \mathrm{~mL} / \mathrm{min}$ \\
\hline \multicolumn{3}{|l|}{ Opioids } \\
\hline Tramadol & $\begin{array}{l}50 \mathrm{mg} \text { orally every } 6 \text { hours as needed } \\
\text { for mild to moderate pain }\end{array}$ & $\begin{array}{l}\text { Use } 25 \mathrm{mg} \text { if creatinine clearance rate is }<60 \\
\mathrm{~mL} / \mathrm{min}\end{array}$ \\
\hline Oxycodone & $\begin{array}{l}2.5-5 \mathrm{mg} \text { orally every } 4-6 \text { hours as } \\
\text { needed for severe pain }\end{array}$ & $\begin{array}{l}\text { Start with } 2.5 \mathrm{mg} \text { if creatinine clearance rate } \\
\text { is }<60 \mathrm{~mL} / \mathrm{min}\end{array}$ \\
\hline \multirow[t]{2}{*}{ Hydromorphone } & $\begin{array}{l}0.25 \mathrm{mg} \text { intravenously every } \\
4-6 \text { hours as needed }\end{array}$ & $\begin{array}{l}\text { Preferable to morphine, since morphine's } \\
\text { metabolites can accumulate in patients with } \\
\text { impaired renal function }\end{array}$ \\
\hline & & $\begin{array}{l}\text { Respiratory depression, delirium, urinary re- } \\
\text { tention, sedation, nausea and vomiting, and } \\
\text { constipation are side effects of all opioids. } \\
\text { Elderly patients may be particularly vulner- } \\
\text { able to changes in mental status with opioids }\end{array}$ \\
\hline
\end{tabular}

In our practice, we consider the elderly patient with hip fracture to be at increased risk; we do not order preoperative BNP testing but proceed as if the BNP were elevated and follow serial troponin levels postoperatively in the patients at highest risk.

Shared decision-making, involving the patient and the family, is critical in a patient with a high-risk cardiac condition to explain the elevated risk of morbidity and death. We offer surgery for high-risk patients, involving cardiac anesthesiology in the management, and admission to the intensive care unit postoperatively if needed.

\section{PERIOPERATIVE INTERVENTIONS THAT MAY AFFECT OUTCOMES}

\section{Anesthesia type}

Studies comparing anesthesia techniques for hip fracture repair have had conflicting results. One large database study found that regional anesthesia reduced the incidence of pulmonary complications and conferred lower odds of mortality than general anesthesia. ${ }^{22}$ However, the same researcher in a subsequent retrospective database study reported no difference in mortality based on anesthesia technique. ${ }^{23}$

Current practices vary by institution, and the decision is typically made after the patient, surgeon, anesthesiologist, and consultants discuss the risks and benefits of each technique as they relate the specific patient.

\section{Pain control}

An opioid-sparing strategy is recommended for optimal perioperative pain control. Neuraxial blockade and peripheral nerve blocks provide the best combination of pain control with the least amount of sedation. ${ }^{24}$ 
Acetaminophen, in scheduled intravenous or oral doses, is associated with shorter hospital stay, lower pain levels, less opioid use, fewer missed physical therapy sessions, and higher rate of discharge to home. ${ }^{25}$

Nonsteroidal anti-inflammatory drugs provide effective analgesia but can be problematic in elderly patients with stage 3 chronic kidney disease (glomerular filtration rate $<60$ $\mathrm{mL} / \mathrm{min}$ ) or higher, given the risk of perioperative acute kidney injury. ${ }^{26}$ In a cohort of geriatric trauma patients over a 6 -year period, these drugs were associated with decreased opioid requirements without an overall increase in bleeding. ${ }^{27}$ We generally avoid nonsteroidal anti-inflammatory drugs in patients with preexisting renal dysfunction.

Gabapentinoids have not been shown to help with pain and may not have a favorable risk-benefit ratio in the elderly. ${ }^{28}$

Muscle relaxants, anticholinergics, and benzodiazepines may increase the risk of delirium when used for perioperative pain.

Table 2 lists the preferred pain control regimens used at our institution.

\section{Nerve blocks}

Enhanced

recovery

protocols have

been used

in Europe

for 20 years

over a wide

range

of surgeries
Peripheral nerve blocks provide better analgesia than opioids alone. Common targets include the femoral nerve and fascia iliaca. Benefits are lower risk of pneumonia, shorter time to ambulation, less postoperative cognitive dysfunction, lower analgesia cost, and less opioid use. To date, studies have been small, and there are not enough data to determine if other outcomes such as delirium are affected. ${ }^{24}$

Effective control of postoperative pain using multimodal analgesia prevents delirium, encourages early participation in physical therapy, and reduces length of stay, hospitalacquired complications, and subsequent institutionalization. ${ }^{29}$

\section{Delirium}

The incidence of delirium after surgery ranges from $10 \%$ to $65 \%,{ }^{29}$ and increases total cost by $50 \%$ as a result of longer length of stay, more nursing care, and more testing. ${ }^{30}$ Risk factors include multiple medical comorbidities, prolonged hospitalization, decreased mobility, and need for discharge into a facility. ${ }^{29}$

A Cochrane review of comprehensive geriatric assessments did not find an improvement in the incidence of delirium with nonpharmacologic interventions, but did find highquality evidence for reduction in discharges to institutional facilities and moderate-quality evidence for mortality reduction. ${ }^{31}$

Simple nonpharmacologic interventions to prevent delirium include an adequate sleep protocol, use of eyeglasses or hearing aids, minimizing urinary catheters, early mobility and daily physical activity, maintaining hydration, and avoidance of constipation. Prophylactic antipsychotics are not recommended. ${ }^{31}$

\section{PREOPERATIVE ANTICOAGULATION MANAGEMENT}

Hip fracture repair carries an intermediate risk of bleeding, for which transfusion is often required. Anticoagulation management is discussed below. ${ }^{32}$

\section{Antiplatelet agents}

Patients receiving aspirin as primary prevention of cardiovascular disease. Aspirin may be discontinued even though the effect on bleeding is negligible. ${ }^{32}$

Patients receiving antiplatelet drugs as secondary prevention. Aspirin should be continued, as the effect on perioperative bleeding is minimal. Clopidogrel, used by itself, should also be continued, as there is no significant increase in bleeding, mortality, need for blood transfusion, length of surgery, or length of stay. ${ }^{32}$

In a prospective study of 1,225 patients receiving clopidogrel, delaying hip fracture repair led to a higher mortality rate: $29 \%$ for those who had surgery delayed vs only $4 \%$ for those who had immediate repair. ${ }^{33}$

Patients on dual antiplatelet therapy: aspirin plus clopidogrel, ticagrelor, or prasugrel. It is essential to know why the patient is receiving dual antiplatelet therapy. Typical reasons include an acute coronary syndrome during the previous 12 months, and a coronary stent implant.

\section{Recommendations on dual antiplatelet therapy}

- After a recent acute coronary syndrome event: ideally, dual antiplatelet therapy should be continued for 12 months after an event. If no stents are placed, the P2Y12 inhibitor (eg, clopidogrel) may be stopped earlier. ${ }^{32}$ 


\section{TABLE 3}

\section{Surgical repair of acute hip fracture: Indications for bridging therapy}

\section{Mechanical valves}

Mechanical mitral valve

Mechanical aortic valve in a patient with atrial fibrillation

Mechanical tricuspid valve

Mechanical aortic valve in a patient in sinus rhythm if it is anticipated that warfarin will not be promptly resumed after surgery

\section{Atrial fibrillation}

$\mathrm{CHA}_{2} \mathrm{DS}_{2}-\mathrm{VASC}^{\mathrm{a}}$ score 7-9 without additional bleeding risks: major bleeding event or intracerebral hemorrhage $<3$ months ago; international normalized ratio above the therapeutic range; prior bleeding event from previous bridging

Any history of stroke or transient ischemic attack (ischemic or cardioembolic)

\section{Venous thromboembolism (VTE)}

VTE event within 3 months

Severe thrombophilia with history of VTE or recurrent VTE (protein C or S deficiency, antithrombin deficiency, antiphospholipid antibodies, homozygous factor V Leiden, or multiple abnormalities); consider bridging for VTE in other thrombophilias (heterozygous factor V Leiden, heterozygous factor II mutation)

History of VTE during discontinuation of anticoagulation

${ }^{a} \mathrm{CHA}_{2} \mathrm{DS}_{2}-\mathrm{VASC}=1$ point each for congestive heart failure, hypertension, age 65-74, diabetes mellitus, vascular disease (coronary artery disease, peripheral arterial disease, aortic aneurysm), female sex; 2 points for age $\geq 75$ and for prior stroke or transient ischemic attack (total possible points 9).

Based on information in references 38

- After recent coronary stenting, with or without a recent acute coronary syndrome event: minimum of uninterrupted dual antiplatelet therapy for 1 month after baremetal stent placement, or 3 to 6 months of uninterrupted dual antiplatelet therapy for a drug-eluting stent. ${ }^{32}$

There are few studies of dual antiplatelet therapy in acute hip fracture repair. In a study of 122 patients on dual antiplatelet therapy at the time of hip fracture repair, there was a similar risk of transfusion, independent of time to operation. ${ }^{34}$ Dual antiplatelet therapy was associated with a higher probability of major complications in early surgery. Delays to surgery for those on dual antiplatelet therapy led to higher mortality rate at 30 days. ${ }^{34}$ It is unclear if the higher complication rate from early surgery was from blood loss or from the medical complications resulting from the fracture.
The guidelines of the American Society of Regional Anesthesia and Pain Medicine suggest waiting 5 to 7 days before performing spinal anesthesia in patients taking clopidogrel or ticagrelor, and 7 to 10 days for patients taking prasugrel. Thus, it is impractical to delay surgery in order to perform spinal anesthesia, especially given the equivocal evidence thus far. ${ }^{35}$ We follow the guidelines outlined above on continuation of dual antiplatelet therapy through the perioperative period. ${ }^{32}$ For indications other than coronary stents or recent acute coronary syndrome, we typically continue aspirin alone in the perioperative period.

\section{Warfarin}

For a patient taking warfarin, we typically withhold 1 dose and consider giving vitamin $\mathrm{K} 2.5$ to $5 \mathrm{mg}$ if the international normalized ratio (INR) is greater than 1.8 before surgery; 
the goal ratio is 1.5 for surgery, and within normal range if neuraxial anesthesia is planned. In a retrospective study of patients on warfarin, delaying surgery by more than 48 hours to allow INR normalization increased the risk of mortality 1.5 times over those sent to surgery within 48 hours. ${ }^{36}$

For the patient at very high thrombotic risk (Table 3), ${ }^{37,38}$ heparin is used as an anticoagulation bridge. Timing of bridging should involve multidisciplinary conversation with orthopedics and cardiology. 37,38

\section{Direct-acting oral anticoagulants}

Surgery must be delayed for 24 hours. For patients with acute renal failure, there should be a discussion between orthopedics, cardiology, and anesthesiology regarding delaying the procedure for 48 hours or using a reversal agent.

Patients receiving these drugs have experienced longer delays to surgery than those receiving warfarin (6.9 hours vs 39.4 hours).$^{39}$

\section{PREVENTING VENOUS THROMBOEMBOLISM}

According to the 2012 American College of Chest Physicians guidelines for prevention of venous thromboembolism in orthopedic surgery patients, the following medications have been approved for prophylaxis after hip fracture surgery: enoxaparin, fondaparinux, aspirin, and vitamin $\mathrm{K}$ antagonists. Table 4 presents dosing recommendations.

Enoxaparin is first-line, as it is highly effective and poses has a low risk of bleeding. ${ }^{37} \mathrm{We}$ use it as our preferred agent.

Data are lacking on the use of direct-acting oral anticoagulants in patients with acute hip fracture, and they are not yet approved for this by the US Food and Drug Administration. Most studies involving these agents included only patients undergoing elective total hip and knee replacement. ${ }^{39}$

Prophylaxis should be continued for 35 days, because the risk of venous thromboembolism is high $(4.3 \%)$ in the first 5 weeks after hip fracture without prophylaxis. ${ }^{37,40}$

An intermittent pneumatic compression device should be used for 18 hours per day in addition to pharmacologic prophylaxis. ${ }^{37}$ If surgery is delayed, enoxaparin should be initiated at the time of presentation and continued up until 12 hours before surgery. Venous thromboembolism prophylaxis should be resumed 12 hours postoperatively, except for warfarin, which should be started the night of surgery.

Aspirin is also an option. ${ }^{37}$ However, a meta-analysis of 8 randomized controlled trials comparing aspirin and anticoagulants in patients undergoing major lower extremity orthopedic surgery found a nonsignificant trend toward fewer episodes of deep vein thrombosis with anticoagulants after hip fracture repair, although the risk of bleeding was lower with aspirin. ${ }^{41}$

\section{ENHANCED RECOVERY PATHWAYS}

Enhanced recovery protocols have been used in Europe for about 20 years over a wide range of surgeries. Many of the recommendations in this review are aligned with such protocols, which have been shown to benefit the geriatric population. ${ }^{42}$

Principles of enhanced recovery pathways include avoiding a preoperative catabolic fasting state and resultant hypoglycemia. ${ }^{42}$ Clear carbohydrate drinks up to 2 hours before surgery can reduce delirium and acute kidney injury and minimize thirst and anxiety. Reduction of opioid use and the use of regional anesthesia whenever possible are other principles.

Intraoperatively, the goal is euvolemia without fluid overload. Postoperatively, the emphasis is on early removal of drains and tubes, continued use of peripheral nerve blocks, and multimodal analgesia to minimize need for opioids, as well as on early mobilization and ambulation and adequate nutrition. Oral nutritional supplementation is recommended in patients with hip fracture who are malnourished or at risk of undernutrition, as these factors increase the risks of fracture nonunion and death. ${ }^{26}$

A large multicenter study ${ }^{43}$ of an enhanced recovery pathway in 5,002 patients with acute hip fractures found significantly higher rates of discharge to home with early ambulation and decreased opioid use.

\section{COMANAGEMENT}

Comprehensive interdisciplinary care in a geriatric ward has been shown to significantly 
TABLE 4

Prophylaxis of venous thromboembolism in elderly hip fracture patients

\begin{tabular}{lll} 
Drug & Dosing and route of administration & $\begin{array}{l}\text { FDA-approved for } \\
\text { VTE prophylaxis? }\end{array}$ \\
\hline $\begin{array}{l}\text { Low-molecular-weight } \\
\text { heparin }\end{array}$ & Enoxaparin $40 \mathrm{mg}$ subcutaneously daily & Yes \\
\hline Fondaparinux & $2.5 \mathrm{mg}$ subcutaneously daily & Yes \\
\hline Warfarin & $\begin{array}{l}3-5 \mathrm{mg} \text { by mouth daily for goal international } \\
\text { normalized ratio 2-3 }\end{array}$ & Yes \\
\hline Unfractionated heparin & $\begin{array}{l}5,000 \mathrm{U} \text { every } 8 \text { hours, every } 12 \text { hours for patients } \\
\text { weighing }<50 \mathrm{~kg}\end{array}$ & Yes \\
& Use if creatinine clearance rate is $<230 \mathrm{~mL} / \mathrm{min}$ & \\
\hline Aspirin & $\begin{array}{l}\text { Unclear, dosing ranges from } 81 \mathrm{mg} \text { orally twice a day } \\
\text { for creatinine clearance rate }<30 \mathrm{~mL} / \mathrm{min},\end{array}$ & No \\
& to $325 \mathrm{mg}$ orally twice a day & \\
\hline Apixaban & $2.5 \mathrm{mg}$ orally twice a day & No \\
\hline Dabigatran & $150 \mathrm{mg}$ orally daily & No \\
\hline Rivaroxaban & $10 \mathrm{mg}$ orally daily & No \\
\hline
\end{tabular}

FDA = US Food and Drug Administration; VTE = venous thromboembolism

improve mobility, activities of daily living, and quality of life compared with routine care in an orthopedic ward. ${ }^{44}$ The length of stay and complications were significantly reduced in the comprehensive geriatric care group, and significantly more patients in this group were discharged directly home.

We recommend consideration of geriatric medicine consultation if there is no geriatric ward or unit for acute care for elderly patients available, to improve outcomes in this population such as discharge to home and reduction in mortality. ${ }^{29}$

\section{TAKE-HOME MESSAGES}

In the elderly, acute hip fracture poses significant risks of illness and death. An expedited medical evaluation to ensure operative repair within 24 to 48 hours of admission is recommended for improved outcomes, and the pa- tient's use of anticoagulants before admission should not delay surgery. Guidelines regarding consultation and cardiac testing should be followed, as routine testing is unlikely to produce a measurable impact on outcomes.

Multimodal analgesia, regional anesthesia, enhanced recovery pathways, and delirium precautions are paramount to producing the best outcomes.

Risk factors contributing to acute hip fracture such as chronic osteoporosis and frailty are often not addressed during the inpatient stay. On discharge, patients should be referred for pharmacologic treatment of osteoporosis, advised on calcium and vitamin D supplementation, and referred for physical therapy to prevent future fractures. ${ }^{29}$

\section{DISCLOSURES}

The authors report no relevant financial relationships which, in the context of their contributions, could be perceived as a potential conflict of interest.
Interdisciplinary care in a geriatric ward significantly improves mobility, activities of daily living, and quality of life 


\section{ACUTE HIP FRACTURE}

\section{REFERENCES}

1. Bhandari M, Swiontkowski M. Management of acute hip fracture. N Engl J Med 2017; 377(21):2053-2062. doi:10.1056/NEJMcp1611090

2. Abrahamsen B, van Staa T, Ariely R, Olson M, Cooper C. Excess mortality following hip fracture: a systematic epidemiological review. Osteoporos Int 2009; 20(10):1633-1650.

doi:10.1007/s00198-009-0920-3

3. Haentjens $\mathbf{P}$, Magaziner J, Colón-Emeric CS, et al. Meta-analysis: excess mortality after hip fracture among older women and men. Ann Intern Med 2010; 152(6):380-390. doi:10.7326/0003-4819-152-6-201003160-00008

4. Shoda $N$, Yasunaga $H$, Horiguchi $H$, et al. Risk factors affecting inhospital mortality after hip fracture: retrospective analysis using the Japanese Diagnosis Procedure Combination Database. BMJ Open 2012; 2(3):e000416. doi:10.1136/bmjopen-2011-000416

5. Pincus D, Ravi B, Wasserstein D, et al. Association between wait time and 30-day mortality in adults undergoing hip fracture surgery. JAMA 2017; 318(20):1994-2003. doi:10.1001/jama.2017.17606

6. Hip Fracture Accelerated Surgical Treatment and Care Track (HIP ATTACK) Investigators. Accelerated care versus standard care among patients with hip fracture: the HIP ATTACK pilot trial. CMAJ 2014; 186(1):E52-E60. doi:10.1503/cmaj.130901

7. Seong YJ, Shin WC, Moon NH, Suh KT. Timing of hip-fracture surgery in elderly patients: literature review and recommendations. Hip Pelvis 2020; 32(1):11-16. doi:10.5371/hp.2020.32.1.11

8. Boddaert J, Raux M, Khiami F, Riou B. Perioperative management of elderly patients with hip fracture. Anesthesiology 2014; 121(6):1336-1341. doi:10.1097/ALN.0000000000000478

9. Swart E, Kates S, McGee S, Ayers DC. The case for comanagement and care pathways for osteoporotic patients with a hip fracture. J Bone Joint Surg Am 2018; 100(15):1343-1350. doi:10.2106/JBJS.17.01288

10. Umpierrez GE, Pasquel FJ. Management of inpatient hyperglycemia and diabetes in older adults. Diabetes Care 2017; 40(4):509-517. doi:10.2337/dc16-0989

11. Spahn DR. Anemia and patient blood management in hip and knee surgery: a systematic review of the literature. Anesthesiology 2010; 113(2):482-495. doi:10.1097/ALN.0b013e3181e08e97

12. Carson JL, Terrin ML, Noveck $\mathrm{H}$, et al. Liberal or restrictive transfusion in high-risk patients after hip surgery. N Engl J Med 2011; 365(26):2453-2462. doi:10.1056/NEJMoa1012452

13. Hong SE, Kim TY, Yoo JH, et al. Acute kidney injury can predict inhospital and long-term mortality in elderly patients undergoing hip fracture surgery. PLoS One 2017; 12(4):e0176259. doi:10.1371/journal.pone.0176259

14. Fleisher LA, Fleischmann KE, Auerbach AD, et al. 2014 ACC/AHA guideline on perioperative cardiovascular evaluation and management of patients undergoing noncardiac surgery: a report of the American College of Cardiology/American Heart Association Task Force on practice guidelines. J Am Coll Cardiol 2014; 64(22):e77e137. doi:10.1016/j.jacc.2014.07.944

15. Duceppe E, Parlow J, MacDonald P, et al. Canadian Cardiovascular Society guidelines on perioperative cardiac risk assessment and management for patients who undergo noncardiac surgery. Can J Cardiol 2017; 33(1):17-32. doi:10.1016/j.cjca.2016.09.008

16. Mutlu H, Bilgili F, Mutlu S, Karaman O, Cakal B, Ozkaya U. The effects of preoperative non-invasive cardiac tests on delay to surgery and subsequent mortality in elderly patients with hip fracture. J Back Musculoskelet Rehabil 2016; 29(1):49-54 doi:10.3233/BMR-150595

17. Luttrell K, Nana A. Effect of preoperative transthoracic echocardiogram on mortality and surgical timing in elderly adults with hip fracture. J Am Geriatr Soc 2015; 63(12):2505-2509. doi:10.1111/jgs. 13840

18. Smeets SJ, Poeze M, Verbruggen JP. Preoperative cardiac evaluation of geriatric patients with hip fracture. Injury 2012; 43(12):21462151. doi:10.1016/j.injury.2012.08.007

19. Bellas N, Stohler S, Staff I, et al. Impact of preoperative specialty consults on hospitalist comanagement of hip fracture patients. J Hosp Med 2020; 15(1):16-21. doi:10.12788/jhm.3264

20. Roshanov PS, Rochwerg B, Patel A, et al. Withholding versus continuing angiotensin-converting enzyme inhibitors or angiotensin II receptor blockers before noncardiac surgery: an analysis of the vascular events in noncardiac surgery patients cOhort evaluatioN Prospective Cohort. Anesthesiology 2017; 126(1):16-27. doi:10.1097/ALN.0000000000001404

21. Writing Committee for the VISION Study Investigators, Devereaux PJ, Biccard BM, et al. Association of postoperative high-sensitivity troponin levels with myocardial injury and 30-day mortality among patients undergoing noncardiac surgery. JAMA 2017; 317(16):16421651. doi:10.1001/jama.2017.4360

22. Neuman MD, Silber JH, Elkassabany NM, Ludwig JM, Fleisher LA. Comparative effectiveness of regional versus general anesthesia for hip fracture surgery in adults. Anesthesiology 2012; 117(1):72-92. doi:10.1097/ALN.0b013e3182545e7c

23. Neuman MD, Rosenbaum PR, Ludwig JM, Zubizarreta JR, Silber $\mathrm{JH}$. Anesthesia technique, mortality, and length of stay after hip fracture surgery. JAMA 2014; 311(24):2508-2517. doi:10.1001/jama.2014.6499

24. Guay J, Parker MJ, Griffiths R, Kopp SL. Peripheral nerve blocks for hip fractures: a Cochrane Review. Anesth Analg 2018; 126(5):16951704. doi:10.1213/ANE. 0000000000002489

25. Bollinger AJ, Butler PD, Nies MS, Sietsema DL, Jones CB, Endres TJ. Is scheduled intravenous acetaminophen effective in the pain management protocol of geriatric hip fractures?. Geriatr Orthop Surg Rehabil 2015; 6(3):202-208. doi:10.1177/2151458515588560

26. Zhang X, Donnan PT, Bell S, Guthrie B. Non-steroidal anti-inflammatory drug induced acute kidney injury in the community dwelling general population and people with chronic kidney disease: systematic review and meta-analysis. BMC Nephrol 2017; 18(1):256 doi:10.1186/s12882-017-0673-8

27. Haines KL, Fuller M, Vaughan JG, et al. The impact of nonsteroidal anti-inflammatory drugs on older adult trauma patients with hip fractures. J Surg Res 2020; 255:583-593. doi:10.1016/j.jss.2020.05.064

28. Eloy JD, Anthony C, Amin S, Caparó M, Reilly MC, Shulman S. Gabapentin does not appear to improve postoperative pain and sleep patterns in patients who concomitantly receive regional anesthesia for lower extremity orthopedic surgery: a randomized control trial. Pain Res Manag 2017; 2017:2310382. doi:10.1155/2017/2310382

29. Hung WW, Egol KA, Zuckerman JD, Siu AL. Hip fracture manage2194. doi:10.1001/jama.2012.4842

30. Zywiel MG, Hurley RT, Perruccio AV, Hancock-Howard RL, Coyte PC, Rampersaud YR. Health economic implications of perioperative delirium in older patients after surgery for a fragility hip fracture. $J$ Bone Joint Surg Am 2015; 97(10):829-836. doi:10.2106/JBJS.N.00724

31. Eamer G, Taheri A, Chen SS, et al. Comprehensive geriatric assessment for older people admitted to a surgical service. Cochrane Database Syst Rev 2018; 1(1):CD012485. doi:10.1002/14651858.CD012485.pub2

32. Levine GN, Bates ER, Bittl JA, et al. 2016 ACC/AHA Guideline Focused Update on Duration of Dual Antiplatelet Therapy in Patients With Coronary Artery Disease: A Report of the American College of Cardiology/American Heart Association Task Force on Clinical Practice Guidelines: An Update of the 2011 ACCF/AHA/SCAI Guideline for Percutaneous Coronary Intervention, 2011 ACCF/AHA Guideline for Coronary Artery Bypass Graft Surgery, 2012 ACC/AHA/ACP/AATS/ PCNA/SCAI/STS Guideline for the Diagnosis and Management of Patients With Stable Ischemic Heart Disease, 2013 ACCF/AHA Guideline for the Management of ST-Elevation Myocardial Infarction, 2014 AHA/ACC Guideline for the Management of Patients With Non-ST-Elevation Acute Coronary Syndromes, and 2014 ACC/AHA Guideline on Perioperative Cardiovascular Evaluation and Management of Patients Undergoing Noncardiac Surgery. Circulation 2016; 134(10):e123-e155. doi:10.1161/CIR.0000000000000404

33. Wordsworth DR, Halsey T, Griffiths R, Parker MJ. Clopidogrel has no effect on mortality from hip fracture. Injury 2013; 44(6):743-746. 


\section{ACKERMANN AND COLLEAGUES}

doi:10.1016/j.injury.2012.11.028

34. Tarrant SM, Kim RG, McGregor KL, Palazzi K, Attia J, Balogh ZJ. Dual antiplatelet therapy and surgical timing in geriatric hip fracture. J Orthop Trauma 2020; 34(10):559-565. doi:10.1097/BOT.0000000000001779

35. Horlocker TT, Vandermeuelen E, Kopp SL, Gogarten W, Leffert LR, Benzon HT. Regional anesthesia in the patient receiving antithrombotic or thrombolytic therapy: American Society of Regional Anesthesia and Pain Medicine Evidence-Based Guidelines (fourth edition). Reg Anesth Pain Med 2018; 43(3):263-309. doi:10.1097/AAP.0000000000000763

36. Caruso G, Andreotti M, Marko T, et al. The impact of warfarin on operative delay and 1-year mortality in elderly patients with hip fracture: a retrospective observational study. J Orthop Surg Res 2019; 14(1):169. doi:10.1186/s13018-019-1199-5

37. Falck-Ytter Y, Francis CW, Johanson NA, et al. Prevention of VTE in orthopedic surgery patients: Antithrombotic Therapy and Prevention of Thrombosis, 9th ed: American College of Chest Physicians Evidence-Based Clinical Practice Guidelines. Chest 2012; 141(suppl 2):e278S-e325S. doi:10.1378/chest.11-2404

38. Doherty JU, Gluckman TJ, Hucker WJ, et al. 2017 ACC expert consensus decision pathway for periprocedural management of anticoagulation in patients with nonvalvular atrial fibrillation: a report of the American College of Cardiology Clinical Expert Consensus Document Task Force. J Am Coll Cardiol 2017; 69(7):871-898. doi:10.1016/j.jacc.2016.11.024

39. Franklin NA, Ali AH, Hurley RK, Mir HR, Beltran MJ. Outcomes of early surgical intervention in geriatric proximal femur fractures among patients receiving direct oral anticoagulation. J Orthop Trauma 2018; 32(6):269-273. doi:10.1097/BOT.0000000000001146

40. Forster R, Stewart M. Anticoagulants (extended duration) for prevention of venous thromboembolism following total hip or knee replacement or hip fracture repair. Cochrane Database Syst Rev 2016; 3:CD004179. doi:10.1002/14651858.CD004179.pub2

41. Drescher FS, Sirovich BE, Lee A, Morrison DH, Chiang WH, Larson RJ. Aspirin versus anticoagulation for prevention of venous thromboembolism major lower extremity orthopedic surgery: a systematic review and meta-analysis. J Hosp Med 2014; 9(9):579-585. doi:10.1002/jhm.2224

42. Kaye AD, Urman RD, Cornett EM, et al. Enhanced recovery pathways in orthopedic surgery. J Anaesthesiol Clin Pharmacol 2019; 35(suppl 1):S35-S39. doi:10.4103/joacp.JOACP_35_18

43. Liu VX, Rosas E, Hwang J, et al. Enhanced recovery after surgery program implementation in 2 surgical populations in an integrated health care delivery system. JAMA Surg 2017; 152(7):e171032. doi:10.1001/jamasurg.2017.1032

44. Prestmo A, Hagen G, Sletvold O, et al. Comprehensive geriatric care for patients with hip fractures: a prospective, randomised, controlled trial. Lancet 2015; 385(9978):1623-1633. doi:10.1016/S0140-6736(14)62409-0

Address: Lily Ackermann, MD, SCM, Department of Medicine, Division of Hospital Medicine, Thomas Jefferson University, Center City Campus, 833 Chestnut St., Suite 701, Philadelphia, PA 19107

lily.ackermann@jefferson.edu 